DOI 10.37882/2223-2982.2020.08.25

\title{
ВЗАИМОДОПОЛНЕНИЕ И КОМБИНИРОВАНИЕ ВИДА ПЕДАГОГИЧЕСКИХ ТЕХНОЛОГИЙ/ПОДХОДОВ ПОЗВОЛЯЕТ СТРОИТЬ ПРОЦЕСС ФОРМИРОВАНИЯ ПРОФЕССИОНАЛЬНЫХ НАВЫКОВ У СТУДЕНТОВ
}

\section{SUPPLEMENTATION AND COMBINATION OF THE TYPE OF PEDAGOGICAL TECHNOLOGIES / APPROACHES ALLOWS TO BUILD THE PROCESS OF FORMATION OF PROFESSIONAL SKILLS IN STUDENTS Ngo Duc Tai}

Summary: In the modern educational process of a higher special educational institution (University), it is necessary and legitimate to implement all four types of technologies (personality-oriented, activity-based, competence-based, contextual approach), since it is their complementarity, their combination that makes it possible to build the process of forming students' professional skills, taking into account the principles of scientific nature, sequence, stages, consistency, continuity. To optimize this process, from our point of view, the most important are activity and developmental problem-search technologies. Informationdevelopmental and personality-oriented technologies play an additional role here, but in some cases they serve as the basis for the implementation of these technologies, which is determined by the specific specifics of the production process and the type of activity that the specialist is engaged in. Research methodology - analysis of scientific literature on a given problem, as well as practical national experience.

Keywords: professional skills, educational process, students, pedagogical technology, professional self-identification and professional selfregulation..
$\Phi$ ормирование профессиональных навыков происходит в тесной взаимосвязи с накоплением теоретических знаний. Не случайно 3.А. Решетова отмечает, что «...вербально выражаемые содержание деятельности, способ и условия ее выполнения и т. д., на основе чего деятельность регулируется и контролируется, есть знание о деятельности, а сама деятельность, выполненная «со знанием», является навыкам» [1]. Однако, мы считаем, что при этом знания все-таки выступают инструментом, обеспечивающим возможность качественно выполнять в дальнейшем профессиональную деятельность.

Например, в ходе выполнения задания по вытачива-

\author{
Нго Дык Тай \\ Аспирант, Тульский государственный университет \\ taitamli_giaogiuc@yahoo.com
}

Аннотация: В современном образовательном процессе высшего специального учебного заведения (Вуза) необходима и правомерна реализация всех четырех видов технологий (личностно-ориентированный, деятельностный, компетентностный, контекстный подход), так как именно их взаимодополнение, комбинирование позволяет строить процесс формирования профессиональных навыков студентов с учетом принципов научности, последовательности, этапности, системности, непрерывности. Для оптимизации данного процесса, с нашей точки зрения, наибольшее значение имеют деятельностные и развивающие проблемно-поисковые технологии. Информационно-развивающие и личностно-ориентированные технологии здесь играют дополнительную роль, но в ряде случаев выступают основой реализации указанных технологий, что определяется конкретной спецификой производственного процесса и видом деятельности, которой занимается специалист. Методология исследования - анализ научной литературы по заданной проблеме, а также практического отечественного опыта.

Ключевые слова: профессиональные навыки, образовательный процесс, студентов, педагогическая технология, профессиональная самоидентификация и профессиональная саморегуляция. нию детали доминирующее значение будут играть профессиональные навыки, сформированные, благодаря реализации деятельностных технологий.

Личностно-ориентированные технологии представлены: организацией работы студентов в сторону доминирования внеаудиторной самостоятельной работы над аудиторной, элективных учебных курсов над обязательными; применением в учебном процессе метода опережающей самостоятельной работы (предшествующая лекциям и семинарам), индивидуализируются профессиональные навыки, сформированные в ходе реализации информационно-развивающих технологий. Тем не менее, в ситуации решения проблем управления 
современными производственно-технологическими системами окажется необходимым комплекс профессиональных навыков, сформированный в результате применения технологий всех четырех групп.

Это доказывает, в частности, технология формирования производственных навыков, предложенная Н.Д. Левитовым и раскрытая на примере обучения студентов трудовым операциям [2]. Выделяются следующие этапы реализации технологии: формирование общего представления об операции; расчленение операции на элементы (конструкция рабочих движений, их темп, регулирование, рабочие усилия); соотнесение сознательных и автоматизированных элементов работы; инструктаж; расширение политехнического кругозора и формирование технического мышления. Этап расчленения операции на элементы подробно рассмотрен СМ. Шабаловым, который особое внимание обращает на методику выполнения элементов операции, с учетом индивидуальных особенностей каждого студента [3]. Следовательно, мы видим, что в данных технологиях также представлены элементы технологий выделенных ранее четырех основных групп.

Остановимся подробнее на процессе формирования профессиональных навыков. В связи с этим представляет интерес методика формирования навыков, предложенная Н.А. Сорокиным [4]. Им выделяется ряд последовательных этапов:

а) объяснение педагогом значения и практической ценности навыки;

б) восстановление в памяти студентов необходимых теоретических знаний и формирование соответствующих правил;

в) показ педагогом правильного выполнения действия;

г) пробные упражнения под руководством педагога;

д) самостоятельные систематические упражнения студентов;

е) выполнение отдельных конкретных заданий с помощью инструктажа;

ж) полная самостоятельность при выполнении заданий;

3) выполнение заданий творческого характера. Последние три этапа выступают как этапы, закрепляющие сформированные навыки.

Эффективность каждого этапа обусловлена успешностью реализации дидактических принципов, среди которых, на наш взгляд, ведущими выступают принципы авансированного поощрения студентов, делегирования полномочий и ответственности, создания ситуаций успеха и достижений, бесконфликтности - максимального сглаживания, устранения конфликтных моментов (по В. Шаталову) [5]. Также большое внимание необходимо уделять установлению и усилению междисциплинарных и внутрипредметных связей (в дискурсе В.С. Безруковой) [6].

Реализация данных принципов при использовании технологий и методик по формированию профессиональных навыков во многом определяется материально-технической базой образовательного учреждения (оснащенность технологическим оборудованием и техническими средствами обучения лабораторий, мастерских; наличием необходимых инструментов) и совершенствованием программно-методического обеспечения учебных занятий. В частности, это предполагает использование технических средств обучения, презентационных технологий и мультимедийных курсов и комплексов, развития самостоятельных форм работы студентов, их научно-исследовательской деятельности, реализации идеи погружения студентов (через систему модульно-блочного обучения).

Задачам углубления и расширения теоретических знаний студентов (фундаментализации обучения), по мнению многих ученых и практиков (напр., Дж. Кэролл, Э.В. Крулль, М.В. Кларин, Д.В. Чернилевский) может отвечать система модульно-блочного обучения.

Данная система обучения предполагает интенсивное «погружение» студентов в информационное поле учебной дисциплины.

Мы разделяем точку зрения В.Ф. Шаталова, считая, что упор на практику следует делать позже, после изучения теоретического раздела. При такой постановке обучения у студентов практически не отмечаются пробелы в знаниях. Отсюда аксиоматичным является утверждение, что при хорошем усвоении знаний у студентов возникает естественное желание расширять и углублять свои познания.

Модульно-блочная система это одна из инновационных технологий образования, эффективность которой подтверждена практикой [7; 8]. В модульно-блочной системе обучения минимальной единицей учебного процесса является цикл (модуль) занятий, а несколько модулей образуют блок. Одним из основных принципов организации блочного и модульного обучения является изучение учебного материала крупными блоками. Содержание образования в контексте данного типа обучения строится не в виде отдельных изолированных и нередко дублирующих друг друга учебных предметов и курсов, а на междисциплинарной основе в виде целостных модулей, обладающих полнотой и законченностью.

Суть реализации данной системы в образовательном учреждении сводится к тому, что расписание учебных занятий представлено двумя учебными дисциплинами. При этом занятия по учебному курсу проводятся еже- 
дневно и не целый семестр, а один месяц (один блок). Затем предусмотрена «свободная неделя», в ходе которой студенты завершают курсовые работы, защищаю их, сдают зачеты и экзамены.

После завершения одного блока начинается второй блок - преподается следующая пара учебных дисциплин.

Обучение по блочной системе позволяет студентам максимально сфокусировать внимание на изучаемом предмете. Эффект «погружения» усиливается в том случае, если удается установить межпредметные связи, то есть выстроить, например, диалог с дисциплиной, изучаемой параллельно. Меж-предметные связи обеспечивают усвоение знаний, форм умений и навыков в определенной системе, способствуют активизации мыслительной деятельности, осуществлению переноса теоретических знаний на учебно-производственную деятельность студентов. В отечественной педагогике в области профессионально-технического образования проблема совершенствования межпредметных связей анализировалась в трудах П.Р. Атутова, С.Я. Батышева, А.П. Беляевой.

Н.В. Тельтевская анализируя междисциплинарные связи как условия развития познавательных интересов и активизации интеллектуальной деятельности студентов делает следующие выводы:

- «реализация междисциплинарных связей в процессе обучения является важнейшим условием формирования системных знаний студентов и способствует активизации познавательной деятельности последних;

- видение и осознание студентами связей между учебными дисциплинами, овладение обобщенным способом познавательной деятельности создает основу для творческого применения усвоенных знаний;

- установление связей между учебными дисциплинами содействует более глубокому и прочному усвоению знаний в связи с видением возможностей их использования в практической деятельности, что, в свою очередь, обусловливает повышение интереса к будущей профессиональной деятельности и понимание необходимости дальнейшего углубления этих знаний.

Установление таких связей выступает одним из важных аспектов профессионального обучения, так как позволяет, по мнению Г.Н. Варковецкой, актуализировать знания и навыки смежных отраслей науки, что часто необходимо при решении творческой производственной задачи [9]. В целом процесс преподавания учебных дисциплин строится таким образом, чтобы студентам чаще приходилось сталкиваться с решением производственно-технологических задач. Задачи подбираются так, чтобы они были напрямую связаны с реальным производственным процессом, с условиями будущего проявления профессиональных навыков студентов. Процесс решения таких задач не только способствует формированию и коррекции профессиональных навыков студентов, но и требует применения знаний, как профильной дисциплины, так и смежных дисциплин. Студент при блочно-модульной системе обучения, получает самое общее структурированное понятие о предмете в целом и дальше может углубиться в той или иной его части самостоятельно.

К числу достоинств блочной системы следует отнести, прежде всего её гибкость, что проявляется:

- в возможности сочетания теоретического и практического осмысления материала учебного курса, использовании активных методов обучения (тренинги, дискуссии, диспуты, проектирование, миниконференции);

- в проведении занятий вне ВУЗа, например на производстве, с целью формирования у студентов первоначальных представлений о профессии, воссоздания реальной среды профессиональной деятельности, привлечения к учебному процессу представителей различных предприятий.

Кроме того, блочное построение учебного процесса позволяет оптимально чередовать теоретическое обучение с организацией и проведением производственных практик в течение учебного года, органично сочетать обучение и трудовую деятельность студентов по специальности.

Блочная система создает благоприятные условия для организации продуктивной самостоятельной работы студентов, дает возможность более рационально использовать аудиторный фонд образовательного учреждения. Открываются новые возможности для оптимизации труда преподавательского состава, например, появляется время (ввиду не занятости в каждом блоке) для проведения масштабных научно-прикладных исследований, командировок и стажировок, прохождения курсов повышения квалификации.

В условиях ограниченности финансовых ресурсов для проведения исследовательской работы преподавателей, помощь ВУЗа в повышении квалификации сотрудников может часто заключаться только в обеспечении возможности профильной стажировки, направлении на курсы, тренинги, организации семинаров и конференций на своей базе.

Положительно о процессе блочного обучения отзываются не только преподаватели, но и студенты, что особенно важно. По их мнению, учебная дисциплина усваивается комплексно, материал лучше осмысливается, происходит постижение разнообразных причин- 
но-следственных связей, зависимостей, мобилизация внутренних резервов и появляется резерв свободного времени в конце семестра [10].

Однако помимо очевидных достоинств у блочной системы имеется и ряд недостатков. Одним из наиболее важных является её «уязвимость». Практически любой сбой в процессе прохождения курса (болезнь преподавателя или студента, форс-мажорные обстоятельства) приводит к потере времени, что восполнить часто просто невозможно. Кроме того, строгие временные рамки затрудняют выполнение студентами творческих проектов, курсовых работ, негативно могут влиять на их качество. Затруднена реализация такой системы и при ограниченности информационного, методического и материально-технического обеспечения учебного процесса, несовершенстве учебно-методического комплексного обеспечения дисциплин (по Л.Г. Семушиной, Н.Г. Ярошенко [11]), при недостаточной сформированности у студентов навыков самостоятельной работы.

Своеобразие самостоятельной работы студентов заключается в том, что его основу составляют самостоятельные действия, которые выполняет студент с помощью преподавателя и без нее, он сам выбирает способы выполнения этих действий, совершает множество операций, контролирует их в соответствии с поставленной целью. Самостоятельная работа рассматривается в отечественной педагогике как высшая форма организации учебной деятельности, и как средство вовлечения студентов в самостоятельную познавательную деятельность, и как совокупность методов, посредством которых достигается приобретение знаний, отношений и навыков, а также решение комплекса воспитательных задач [12; 13]. Особенностью самостоятельной работы является действие самоконтроля - одной из важнейших форм самоидентификации и саморегуляции студента.

Проблема повышения эффективности самостоятельной работы рассматривалась в трудах В.А. Андреева, М.А. Данилова, Б.П. Есипова, И.Я. Лернера, П.И. Пидкасистого, М.Н. Скаткина, А.В. Усовой. Успешное выполнение самостоятельной работы обеспечивается следующими условиями: высокой мотивацией учебного задания, четкой постановкой цели, задач и их ясностью, актуализацией имеющихся знаний, определением алгоритма выполнения задания, проведением индивидуальных и групповых консультаций преподавателем, четкостью и ясностью форм отчетности, рациональностью сроков их представления, а также индивидуализацией и дифференциацией учебных заданий. Создание таких условий возможно только в том случае, если педагог придерживается принципов педагогики сотрудничества, стремится к формированию ситуаций успеха у студентов, использует различные виды авансированного поощрения, повышает самооценку обучающихся, уверенность в

\section{своих силах.}

Применение данного метода обусловлено важностью самостоятельной работы для формирования таких индивидуальных способностей как активность, инициативность, самостоятельность, способность к самообразованию и самоконтролю. Главным достоинством рассматриваемого метода выступает то, что самостоятельная работа всегда завершается определенными результатами.

Поскольку к ним студент приходит самостоятельно, их ценность и значимость осознается острее по сравнению с теми, которые получены в рамках совместной деятельности. Наиболее эффективными формами самостоятельной работы студентов выступают: организация производственного обучения в учебных мастерских, курсовое и дипломное проектирование, включение студентов в самостоятельное выполнение исследовательских, конструкторских, проектных и технологических разработок.

Для развития исследовательской деятельности студентов в высших учебных заведениях создаются научные студенческие общества, деятельность которых традиционно представлена тремя проблемно-исследовательскими группами. В фокусе внимания студентов такие проблемы, как: «Оптимизация производственно-технологического процесса», «Совершенствование узлов, механизмов, инструментальной базы производственно-технологического процесса», «Разработка производственной документации». Благодаря этому студенты оказываются в ситуации проектирования собственной деятельности в избранной ими области с необходимостью анализа, а в дальнейшем защиты результатов своей деятельности. В исследовательских проектах могут принимать участие все: и сильные, и слабые студенты [14]. Эффективность проектной деятельности, с нашей точки зрения, повышается если удается осуществить её связь с программным материалом, активизировать межпредметные связи, что значительно расширяет и углубляет знания студентов.

В целом основа проекта должна быть представлена какой-либо значимой проблемой, решение которой будет способствовать приближению студента к реальным жизненным ситуациям на производстве. Кроме того, проектная деятельность позволяет не только самоактуализироваться студенту, но и проявить свои творческие, организаторские, коммуникативные способности. Проект - это мощный фактор развития у каждого основ работы в команде, в группе. Исследовательское проектирование учит студентов самостоятельно мыслить, создавать алгоритм решения проблемных ситуаций, привлекая для этого знания из разных областей, прогнозировать конечный результат, критически его оценивать, устанав- 
ливать причинно-следственные связи и зависимости. В ходе разработки и реализации проекта осуществляется развитие креативного мышления студентов, основными показателями которого, по мнению Г.Л. Филипповой, являются способность к синтезу нового, к генерации идей и использованию нестандартных способов деятельности, развитая интуиция, фантазия, богатое воображение, высокий уровень гармоничности интеллектуальных операций, способность преодолевать психологическую инерцию и стереотипы мышления [15].

Синтез теоретических и прикладных знаний в ходе подготовки и возможной реализации проектов стимулирует познавательную и профессиональную мотивацию студентов, так как результат проектной деятельности часто можно увидеть в реальной жизни.

Участие в работе научного студенческого общества позволяет выйти студентам на комплексный анализ технологических процессов, проблем современного производства и их решение. Такая работа заставляет задуматься над возможностями совершенствования технологических операций и систем путем внедрения рационализаторских предложений, изобретений, разработки творческих проектов. В таких ситуациях базовые предприятия обычно идут навстречу студентам и после скрупулезного анализа рационализаторского предложения могут пойти на его внедрение [16].

Такой подход способствует не только развитию современных производственных технологий, но главное - создает импульс для развития творчества студентов, привлечения в научном студенческом обществе новых студентов, стимулирует их креативную активность и самостоятельность. Наша педагогическая практика показывает, что студенты, которые принимали активное участие в работе научного студенческого общества - это в дальнейшем высококвалифицированные производственники.

Данному процессу способствует развитие и внедрение в учебный процесс информационных технологий в виде обязательного предмета «Информатика» и спецкурсов, например «Информационные технологии в производственном процессе», что способствует приобретению студентами знаний и навыков, предусмотренных государственными образовательными стандартами высшего профессионального образования второго поколения.

С другой стороны, презентационные технологии и мультимедийные курсы и комплексы позволяют преподавателю оперативно подготовить наглядные пособия по предмету и значительно интенсифицировать усвоение учебного материала, активизировать познавательную деятельность студентов. Использование средств мультимедиа позволяют сделать занятия наглядными и интересными для студентов.

Особое внимание уделяется обеспечению учебного процесса, прежде всего электронными образовательными ресурсами и технологиями, а не традиционными бумажными, что педагогически более целесообразно. Это связано с тем, что электронные образовательные ресурсы содержат значительно больше информации, их использование позволяет значительно (в разы) сократить время на представление учебного материала, его усвоение, формирование определенных профессиональных навыков, при сохранении, а иногда и повышения качества усвоения информации. Например, электронные ресурсы позволяют визуализировать на компьютере учебную информацию об объектах и закономерностях процессов, явлений, как реально протекающих, так и «виртуальных» [17], дают возможность многократного их повторения, моделирования производственных процессов, их самостоятельной коррекции и проверки своих технологических решений.

Кроме того, такие ресурсы позволяют осуществить адаптацию учебного процесса к темпам индивидуального усвоения учебного материала студентом, который при необходимости может в своё свободное время обратиться к интерактивному учебному курсу, получая соответствующую «электронному» помощь и поддержу. Также применяются фото-, видеоматериалы для ознакомления студентов с различными особенностями современного производственного процесса, раскрытия специфики технологических операций.

Преподаватели создают учебно-технологические карты, содержащие информацию о том, какие понятия и законы должны быть усвоены в ходе работы над данным тематическим модулем, в каком учебнике, параграфе и на какой странице можно найти информацию о данных понятиях и законах, при выполнении каких заданий и лабораторных работ можно применять эти знания. Также в отдельной графе технологической карты может быть представлен план всех занятий по модулю.

Применение преподавателями на занятиях разнообразных наглядных средств обучения, в т.ч. видеосюжетов, мобилизует внимание студентов, а в сочетании с вербальными и практическими методами дидактики позволяет задействовать все органы чувств, что позитивно сказывается на качестве учебного процесса. По мнению М. Вертгеймера, качество процесса восприятия определяется «не единичными элементарными ощущениями и их сочетаниями, а всем «полем», действующих на организм раздражителей, структурой воспринимаемой ситуации в целом» [18].

Таким образом, организационно-методическое обеспечение учебных занятий (особенности которого представлены выше) влияет на качество формирования 
профессиональных навыков. При этом успешность формирования профессиональных навыков зависит от того, насколько активно сами студенты участвуют в процессе обучения, занимают ли они субъектную позицию в нем. Не случайно П.П. Блонский еще в прошлом веке писал, что: «...вместо антипсихологической школы активного учителя и пассивно-внимательных детей... пора переходить к школе активных детей и внимательного учителя»
[19]. Эти слова являются актуальными и для высшей специальной и высшей профессиональной школы. Сегодня тем более приоритетной становится стратегия на активизацию личности студентов в профессиональном образовании. Этому способствует специальная организация образовательного процесса с применением активных методов и форм обучения на основе личностно ориентированного и контекстного подходов.

\section{ЛИТЕРАТУРА}

1. Cleary T.J, Zimmerman B.J. Self-regulation differences during athletic practice by experts, non-experts, and novices. J Appl Sport Psychol. 2001;13:185-206.

2. Бызова В.М., Ловягина А.Е. Стили психосоматического поведения у студентов с разными приемами саморегуляции в ситуации экзамена / Экология человека. 2017.

3. Белоусов К.Ю., Панова Е.М. Мониторинг этнической самоидентификации и межэтнической толерантности студентов профессиональных образовательных учреждений Санкт-Петербурга / Alma mater (Вестник высшей школы). 2018.

4. Леонтьева Э.0. Социально-психологический портрет и особенности самоидентификации личности китайских студентов, обучающихся в дальневосточных вузах / Социальные и гуманитарные науки на Дальнем Востоке. 2018.

5. Митрошина П.А., Чеканушкина Е.Н. Физическая активность как средство психологической саморегуляции студента / Актуальные проблемы физического воспитания студентов Материалы Международной научно-практической конференции. 2019. С. 377-381.

6. Бодаева Е.А. Исследование волевой саморегуляции студентов психологического факультета на разных этапах обучения в вузе / Проблемы теории и практики современной психологии Материалы XV ежегодной Всероссийской (с международным участием) научно-практической конференции. 2016. С. 273-275

7. Мелюхин Г.М., Игошев М.В. Применение положений теории социальной идентичности как основа спортивной подготовки студентов / Современные проблемы науки и образования. 2018. № 1. С. 14

8. Мерцалова А.В., Кедич С.И., Чернова Г.Р. Особенности гендерной самоидентификации и самоактуализации студентов / Человек и транспорт. Образование. Психология. Эргономика. Эффективность и безопасность материалы Всероссийской научно-практической конференции с международным участием. Петербургский государственный университет путей сообщения Императора Александра I; Российское психологическое 0бщество. 2018. С. 84-89.

9. Гордеева Т.О., Сычев 0.А. Мотивационные профили как предикторы саморегуляции и академической успешности студентов / Вестник Московского университета. Серия 14: Психология. 2017. № 1. С. 67-87.

10. Нос Т.Н. Умения саморегуляции как личностные качества студентов / современные тенденции развития науки. Современные исследования в психологии и педагогике Материалы международной научно-практической конференции. Ответственный редактор А.А. Зарайский. 2017. С. 39-41

11. Девель Л.А. Сохранение и изучение мирового культурного наследия как благодатная тема для виртуальной практики международной коммуникации, развития языковых навыков и навыков активной семантизации, поликультурной компетенции / Современная наука: актуальные проблемы теории и практики. Серия: Гуманитарные науки. 2018. № 9-2. С. 30-35.

12. Андреева А.Р., Борзилова Н.С. Особенности защитно-совладающего поведения студентов с разным уровнем саморегуляции / теоретические и прикладные аспекты деятельности психологической службы вуза сборник материалов Международной научно-практической конференции. 2017. С. 176-184.

13. Макунина 0.А. Особенности саморегуляции поведения студентов-спортсменов в условиях сочетанной деятельности / физическая культура и спорт в жизни студенческой молодёжи Материалы 2-й международной научно-практической конференции, посвящённой 300-летию города 0мска. - [Электронное издание]. 2016. С. 19

14. Карнаухов Н.В., Карнаухова Т.И. Саморегуляция учебно-познавательной деятельности студентов в условиях музыкально-инструментальной подготовки / Музыкальное и художественное образование в современном мире: традиции и инновации (борник материалов Международной научно-практической конференции Таганрогского института имени А.П. Чехова (филиала) ФГБОУ ВО «Ростовский государственный экономический университет (РИНХ)». 2017. С. 669-677

15. Kumru, A., Thompson, R.A. (2003). Ego Identity Status and Self -Monitoring Behaviour in adolescents. Journal of Adolescent Research, 1 (x), Pp. 1-16, D0I: $10.1177 / 0743558403255066$

16. Телина И.А., Лосева А.А. Социально-психологические аспекты адаптации студентов к образовательным условиям вуза / Профессиональное образование в России и за рубежом. 2018. № 2 (30). С. 132-139.

17. Иванова И.В., Шульман М.Г. Научные представления о саморазвитии личности: философский аспект // Вестник образовательного консорциума. Сер.: Гуманитарные науки. 2014. № 3. C. 57-60. URL: http://www.vestnik-university.com/archives/p13_sectionid/3 (дата обращения: 26.06.2017)

18. Деркач А.А., Сайко Э.В. Потребность В самореализации как феномен социального мира и основание акмеологического развития // Мир психологии. 2008. № 1. C. 218-229. URL: http://psyjournals.ru/mpsi_worldpsy/2008/n1/27688.shtml (дата обращения: 23.06.2017)

19. Бражник Д.Ю., Шутенко Е.Н. Стиль саморегуляции поведения и направленность локуса контроля студентов с различным уровнем академической успеваемости / Электронный научный журнал. 2017. № 1-2 (16). С. 7-13

(c) Нго Дык Тай (taitamli_giaogiuc@yahoo.com).

Журнал «Современная наука: актуальные проблемы теории и практики» 